\title{
Experimental study of a drop "evolution" under conditions of its free fall on a heated surface
}

\author{
Kseniya Batishcseva ${ }^{1, *}$, and Konstantin Ponomarev ${ }^{1}$ \\ ${ }^{1}$ National Research Tomsk Polytechnic University, 634050 Tomsk, Russia
}

\begin{abstract}
Time dependences of distilled water drop diameter were obtained experimentally after its falling on a heated copper substrate from a height of $0.09 \mathrm{~m}$. The temperature of the solid surface $\left(T_{w}\right)$ varied from 333 to $413 \mathrm{~K}$ in steps of $20 \mathrm{~K}$. The effect on the drop dynamics after falling and the maximum ratio of the spreading diameter to the drop diameter in flight ( $\beta_{\max }$ ) were determined.
\end{abstract}

\section{Introduction}

Drop falling is implemented in the technological processes of inkjet printing, spraying, plasmodynamic synthesis, fuel injection in the internal combustion engine, gas turbine operation, drop-cooling systems [1-6]. It is necessary to control their spatial distribution and spreading when they impact the surface in order to prevent the merging of adjacent drops. A drop spreading over a solid surface is found to depend on the gravity forces, inertia, viscosity, friction and surface tension [7-10]. The weight of the drop affects the gravity force; liquid composition affects the viscous friction force and surface tension; mass of liquid and surface roughness on mechanical friction.

The dynamics of a drop on a solid surface is characterized by $\beta=f(\tau)$ [11], where $\beta$ is the ratio of the spreading diameter to the drop diameter in flight dimensionless contact diameter, $\tau$ is a dimensionless time.

The behavior of a liquid on a heated surface was determined by the dimensionless temperature $T^{*}[11]$ :

$$
T^{*}=\frac{T_{w}}{T_{s}}
$$

where $T_{w}$ is the surface temperature, $\mathrm{K} ; T s$ is liquid saturation temperature, $\mathrm{K}$.

The aim of the paper is to determine the dynamics of a drop (change of the geometric shape) of distilled water when it falls freely onto a heated copper surface.

\footnotetext{
* Corresponding author: bka1801@mail.ru
} 


\section{Experimental setup}

Experimental studies were carried out on a polished copper substrate M1. Latter was a solid cylinder with a diameter of $50 \mathrm{~mm}$ and a thickness of $4 \mathrm{~mm}$. The surface of the substrate was polished with diamond pastes and grinding wheels. The roughness was characterized by the mean surface average roughness $(\mathrm{Ra}=0.361 \mu \mathrm{m})$. The substrate was purified with isopropanol followed by rinsing with distilled water.

The scheme of the experimental setup is shown in Fig. 1.

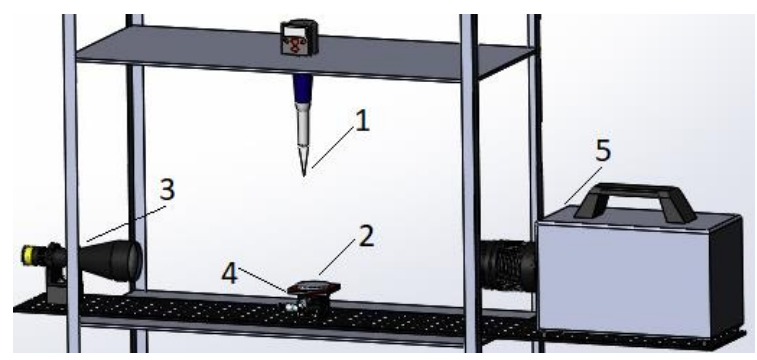

Fig. 1. Schematic diagram of the experimental setup: 1 - syringe dispenser; 2 - substrate; 3 - source of plane-parallel light; 4 - electric heating element; 5 - high-speed video camera.

The distilled water drop with a volume of $10 \pm 0.25 \mu \mathrm{l}$ was formed on the tip of the dispenser (1), a place at a distance of $0.09 \mathrm{~m}$ from the surface of the substrate (2). The source of the plane-parallel light (3) illuminating the drop at the moment of incidence onto the substrate mounted on the electric heating element (4). Shadow images of the drop were obtained with the FastCAMSA1.1 model 675K-M1 high-speed video camera (5) with a shooting speed of 5000 frames per second.

The temperature was recorded by a thermocouple of type K (OMEGA 5TC-TT-K-40-36) standing under the substrate. The thermocouple error under the conditions of the investigated temperature range did not exceed $0.1 \mathrm{~K}$. The substrate temperature varied from 333 to $413 \mathrm{~K}$ $\left(T^{*}=0.6 \div 1.4\right)$ in $20 \mathrm{~K}$ increments.

The drop diameter $\left(D_{0}\right)$ during the fall was determined using expression (3) [11]. While falling, the liquid took the form of a sphere:

$$
D_{0}=\sqrt[3]{\frac{\sigma \cdot \sigma \cdot d_{c}}{\rho \cdot g}}
$$

According to (2), the drop diameter was $D_{0}=2.80 \mathrm{~mm}$ formed by the dispenser with the tip $d_{c}=0.5 \mathrm{~mm}$, under atmospheric pressure and ambient air temperature $T_{\text {air }}=298 \mathrm{~K}$.

Speed $\left(U_{0}\right)$ of the falling drop $U_{0}=1.32 \mathrm{~m} / \mathrm{s}$ was determined by the shadow images analysis results. The results agree well (error $<1 \%$ ) with the free fall speed (3) $U_{0}^{*}=1.324 \mathrm{~m} / \mathrm{s}$ and the empirical equation of K. Range [12] (4) $U_{0}^{* *}=1.324 \mathrm{~m} / \mathrm{s}$ :

$$
\begin{gathered}
U_{0}^{*}=\sqrt{2 \cdot H \cdot g}, \\
U_{0}^{* *}=\sqrt{\frac{g}{A} \cdot\left(1-e^{-2 \cdot A \cdot H}\right)} \text { with } A=\frac{3}{4} \cdot \frac{c_{f} \cdot \rho_{\text {air }}}{\rho_{\text {drop }} \cdot D_{0}},
\end{gathered}
$$


where $H$ is the fall height of the drop, $\mathrm{m} ; c_{f}$ is the ball drag coefficient; $\rho_{\text {air }}$ is the density of the environment (air), $\mathrm{kg} / \mathrm{m}^{3} ; \rho_{\text {drop }}$ is drop density, $\mathrm{kg} / \mathrm{m}^{3}$.

The dimensionless quantity $\left(c_{f}\right)$, called the ball drag coefficient [13] was determined by the formula:

$$
c_{f}=\frac{24}{\mathrm{Re}}+\frac{4}{\sqrt[3]{\mathrm{Re}}}
$$

\section{Results and discussions}

According to the results of experimental studies, a change in the geometric shape of the drop under the conditions of its impact on a heated $\left(T_{w}=333 \div 413 \mathrm{~K}\right)$ copper polished surface was established (Fig. 2-4).

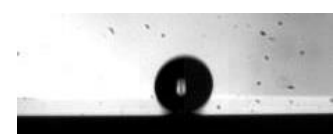

(a) $0 \mathrm{~ms}$

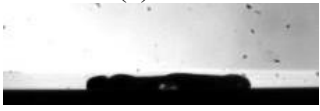

(d) $5 \mathrm{~ms}$

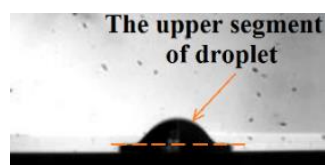

(b) $1 \mathrm{~ms}$

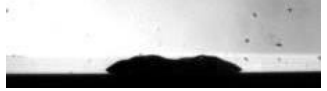

(e) $10 \mathrm{~ms}$

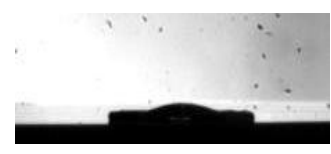

(c) $2 \mathrm{~ms}$

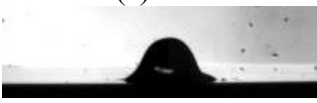

(f) $15 \mathrm{~ms}$

Fig. 2. Change the geometric shape of the drop, at $T_{w}=333 \mathrm{~K}$. Time after the drop touches the surface, ms: (a) $0 \mathrm{~ms}$; (b) $1 \mathrm{~ms}$; (c) $2 \mathrm{~ms}$; (d) $5 \mathrm{~ms}$; (e) $10 \mathrm{~ms}$; (f) $15 \mathrm{~ms}$.

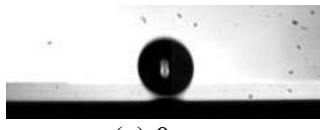

(a) $0 \mathrm{~ms}$

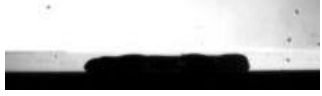

(d) $5 \mathrm{~ms}$

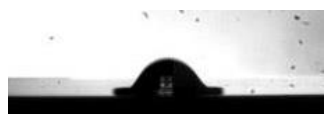

(b) $1 \mathrm{~ms}$

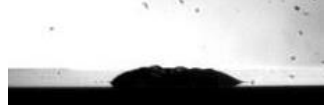

(e) $10 \mathrm{~ms}$

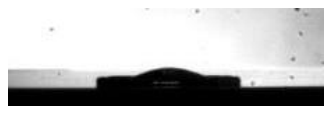

(c) $2 \mathrm{~ms}$

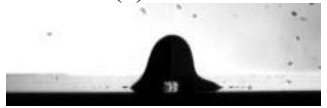

(f) $15 \mathrm{~ms}$

Fig. 3. Change the geometric shape of the drop, at $T_{w}=373 \mathrm{~K}$. Time after the drop touches the surface, ms: (a) $0 \mathrm{~ms}$; (b) $1 \mathrm{~ms}$; (c) $2 \mathrm{~ms}$; (d) $5 \mathrm{~ms}$; (e) $10 \mathrm{~ms}$; (f) $15 \mathrm{~ms}$.

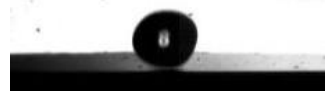

(a) $0 \mathrm{~ms}$

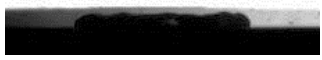

(d) $5 \mathrm{~ms}$

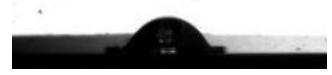

(b) $1 \mathrm{~ms}$

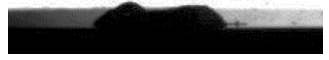

(e) $10 \mathrm{~ms}$

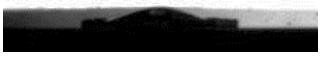

(c) $2 \mathrm{~ms}$

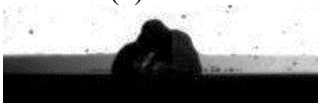

(f) $15 \mathrm{~ms}$

Fig. 4. Change the geometric shape of the drop, at $T_{w}=413 \mathrm{~K}$. Time after the drop touches the surface, ms: (a) $0 \mathrm{~ms}$; (b) $1 \mathrm{~ms}$; (c) $2 \mathrm{~ms}$; (d) $5 \mathrm{~ms}$; (e) $10 \mathrm{~ms}$; (f) $15 \mathrm{~ms}$.

The moment of the drop contact with the surface (Fig. 2 (a)) was taken as the time reference (time $=0 \mathrm{~ms}$ ). From this moment, the drop begins spreading and its upper segment (Fig. 2 (b) without shape changing continues to approach the solid surface at a speed $U_{0}$ 
[14]. The growth rate of the contact diameter decreases due to the viscous friction (the lower layers of the drop are retarded, dragging adjacent faster layers) (Fig. 2 (c)). The liquid molecules on the drop surface attract the liquid from the side in comparison with the ambient air. The surface layer (about 10 A thick), where the molecules approach to move into the depth, exerts pressure on the liquid. The free energy of the surface layer was directed at all points perpendicular to the surface and tends to reduce it to a minimum.

The maximum contact diameter $\left(D_{\max }\right)$ was reached when the drop spreads into a thin film (Fig. 2 (d)). The latter begins to compress (Fig. 2 (e)) due to capillary forces. At the center of the film, the liquid moves upward, giving it the shape of a drop again (Fig. 2 (f)). Then the contact diameter was reduced to achieve a final equilibrium diameter $D_{c}$ that was smaller that $D_{\max }$.

We note that at substrate temperatures $\left(T_{w} \geq 373 \mathrm{~K}\right.$ ) after reaching $D_{\max }$ the liquid film was compressed into a drop, but its surface becomes wave-like (Fig. 3 (e), Fig. 4 (e)). The latter can be explained as follows. The liquid on the drop periphery overheats. When the liquid was heated to a temperature at which the film begins to "bounce" off the surface, the liquid at the edges of the drop moves upward, entraining the liquid behind it. The drop surface prevents the rupture of the layer. At the maximum surface temperature $\left(T_{w}=413 \mathrm{~K}\right)$ small drops were released into the ambient air from the drop (Fig. 4 (f)).

To quantitatively estimate the drop dynamics after falling on the heated surface in Fig. 5, the dependences of the dimensionless diameter of the drop spread $\beta=D / D_{0}$, dimensionless time $\tau=t \cdot U_{0} / D_{0}$, and dimensionless temperature $T^{*}=T_{w} / T_{S}=0.6 \div 1.4$ are used.

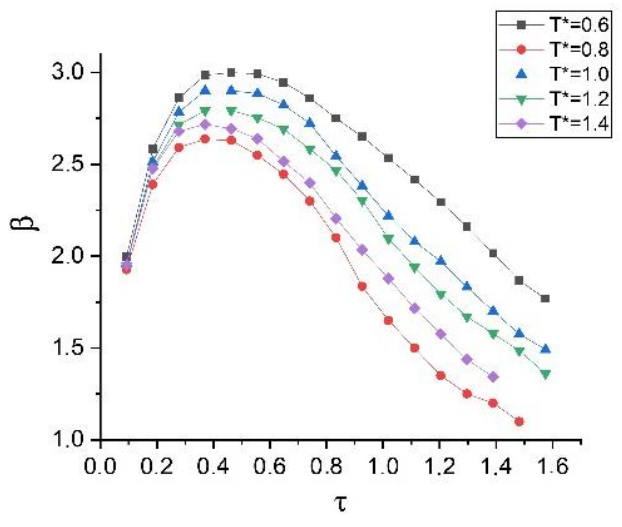

Fig. 5 Dimensionless drop spreading diameter from a dimensionless time at $T^{*}=0.6 \div 1.4$.

Dependencies (Fig. 5) show maximums of the dimensionless diameter $\left(\beta_{\max }\right)$. With a small kinetic energy of drops and low substrate surface temperatures $\left(T^{*} 0.6 \div 0.8\right) \beta_{\max }$ of spreading drop decreases from 3.00 to 2.63 (Fig. 5). The increase in the wall temperature increases the part of the heat accumulated by the expanding drop due to the high heat capacity. The evaporation rate from the drop-free surface increases, cooling the latter. Under such conditions, the drop surface tension and its viscosity increase, not allowing the latter to greatly spread.

At the substrate temperature $T_{w}=373 \mathrm{~K}$ the dimensionless drop spreading diameter increased to 2.90. This was due to the fact that when the drop spreads its periphery with the lowest height warms up faster than the liquid in the center. The drop warmed up quickly in 
contact with the substrate. The increase in temperature reduced the effect of capillary forces and viscous friction forces, which led to rising. The drop did not break up into small parts.

At surface temperatures above the boiling point of the liquid $\left(T^{*}=1.2 \div 1.4\right) \beta_{\max }$ decreases up to 2.78 at $T_{w}=413 \mathrm{~K}$. Under these conditions, steam bubbles of micron size are created on the drop periphery heated to a temperature higher $373 \mathrm{~K}$ which bursting, separating the microdrops from the liquid. The higher the substrate temperature the more microbubbles are generated, and the secondary drops are more separated. The maximum drop contact spreading diameter decreases.

\section{Conclusion}

Based on the results of the experimental studies the dependences of the dimensionless diameter $(\beta)$ of the distilled water drop spreading on time $(\tau)$ were established. The maximum dimensionless diameter $\left(\beta_{\max }\right)$ under these conditions was in the range $\beta_{\max }$ $=2.63 \div 3.00$.

A qualitative and quantitative analysis of the drop dynamics after its fall on a heated polished $(R a=0.361 \mu \mathrm{m})$ copper substrate was carried out. It was found that at a dimensionless temperature $T^{*}<1$ upon reaching $\beta_{\max }$ a liquid film was compressed in a drop with a regular rounded shape. When $T^{*}=1$ the surface of the compressed drop was a waveform. The latter was due to overheating and the motion of the liquid in the drop. When $T^{*}>1$ in addition to the drop waveform it was possible to observe the formation of steam microbubbles in it, which, when detached, separate microdrops from the liquid bulk. The latter was the cause of the decrease in $\beta_{\max }$ with growth of $T_{w}$.

The reported study was supported by RFBR, research project No. 18-38-00315 mol_a.

\section{References}

1. V. E. Nakoryakov, S. Ya. Misyura, S. L. Elistratov, R. A. Dekhtyar, J. Eng. Thermophys. 23, 257 (2014), DOI: 10.1134/S1810232814040018

2. V. E. Nakoryakov, S. Y. Misyura, J. Eng. Thermophys. 25, 24 (2016), DOI: $10.1134 / \mathrm{S} 1810232816010033$

3. M. Popov, O. Maniv, MATEC Web Conf. 141, 01060 (2017), DOI: 10.1051/matecconf/201714101060

4. A. Sivkov, A. Pak, I. Shanenkov, Y. Kolganova, I. Prosvirin, Adv. Mater. Res. 880, 36 (2014), DOI: 10.4028/www.scientific.net/AMR.880.36

5. M. V. Piskunov, P. A. Strizhak, Exp. Therm. Fluid Sci. 91, 103 (2018), DOI: 10.1016/j.expthermflusci.2017.10.018

6. D. O. Glushkov, D. P. Shabardin, P. A. Strizhak, K. Yu. Vershinina, Fuel Process. Technol. 143, 60 (2016), DOI: 10.1016/j.fuproc.2015.11.014

7. E. G. Orlova, D. V. Feoktistov, G. V. Kuznetsov, K. O. Ponomarev, Eur. J. Mech. B Fluids 68, 118 (2018), DOI: 10.1016/j.euromechflu.2017.12.002

8. D. V. Feoktistov, E. G. Orlova, A. G. Islamova, MATEC Web Conf. 23, 01054 (2015), DOI: $10.1051 /$ matecconf $/ 20152301054$ 
9. K. A.Batischeva, E. G. Orlova, D. V. Feoktistov, EPJ Web Conf. 82, 01055 (2015), DOI: 10.1051/epjconf/20158201055

10. D. V. Zaitsev, D. P. Kirichenko, V. S. Ajaev, O. A. Kabov, Phys. Rev. Lett. 119, 094503 (2017), DOI: 10.1103/PhysRevLett.119.094503

11. M. Bornhorst, O. Deutschmann, Int. J. Heat Fluid Flow 69, 55 (2018), DOI: 10.1016/j.ijheatfluidflow.2017.10.007

12. K. Range, F. Feuillebois, J. Colloid Interface Sci. 203, 16 (1998), DOI: 10.1006/jcis. 1998.5518

13. N. A. Fuchs, The Mechanics of Aerosols (Ed. Pergamon Press, London, 1964)

14. M. B. Lesser, Proc. R. Soc. Lond. A 377, 289 (1981), DOI: 10.1098/rspa.1981.0125 